\title{
Case of cytomegalovirus retinitis aggravated by sub-Tenon injection of triamcinolone acetonide with subsequent metastatic liver cancer
}

This article was published in the following Dove Press journal:

Clinical Ophthalmology

28 February 2013

Number of times this article has been viewed

\author{
Yumiko Yamamoto' \\ Yoshitake Kato ${ }^{2}$ \\ Hitoshi Tabuchi ${ }^{2}$ \\ Atsuki Fukushima! \\ 'Department of Ophthalmology \\ and Visual Science, Kochi Medical \\ School, Kochi, Japan; ${ }^{2}$ Department \\ of Ophthalmology, Tsukazaki \\ Hospital, Hyogo, Japan
}

Correspondence: Yumiko Yamamoto Department of Ophthalmology and Visual Science, Kochi Medical School, Kohasu, Oko-cho, Nankoku, Kochi, Japan 7838505

Tel +8I $88880239 \mid$

Fax +8I 888802392

Email hiroyumi@orange.ocn.ne.jp

\begin{abstract}
We report a case of cytomegalovirus (CMV) retinitis in an immunocompetent patient who was resistant to antiviral treatment, and in whom fatal metastatic liver cancer was later detected. A 74-year-old Japanese man visited our ophthalmology clinic in May 2011. He had a history of well controlled type 2 diabetes and colon cancer, and underwent successful surgical treatment in 2008. In April 2011, he was diagnosed with uveitis affecting his left eye and received posterior sub-Tenon injection of triamcinolone acetonide. He was referred to us because of aggravation of the retinal lesion. Funduscopic examination of the left eye revealed arcuate, whitish, necrotizing retinitis with hemorrhage along the temporal arcade of the retina. Polymerase chain reaction of the aqueous fluid was positive for CMV DNA. Because of diagnosis of CMV retinitis in his left eye, he was referred to an internist and investigated for systemic CMV infection or any serious disease which could cause immunocompromise, but neither was detected. Despite an intensive course of intravitreous ganciclovir and oral valganciclovir, the retinitis did not resolve. In June 2012, 14 months after the initial ocular symptoms, metastatic liver cancer was found and the patient passed away. When CMV retinitis is resistant to antiviral treatment or recurs in an immunocompetent patient, it is important that ophthalmologists undertake systemic investigation for occult malignancy.
\end{abstract}

Keywords: cytomegalovirus, retinitis, uveitis, immunocompromised, immunocompetent, triamcinolone acetonide, diabetes, ganciclovir, valganciclovir

\section{Introduction}

Cytomegalovirus (CMV) retinitis is one of the most common opportunistic ocular infections in immunocompromised patients. However, there have been recent reports that immunocompetent patients can also develop CMV retinitis. These patients had common risk factors, including old age, a history of intraocular surgery, intraocular administration of steroids, and diabetes. The ocular prognosis of these patients is not serious and the retinitis is usually treated successfully by antiviral agents, eg, ganciclovir and valganciclovir. Here we report a case of CMV retinitis in an immunocompetent patient in whom initial antiviral treatment was effective, but when therapy was discontinued, the retinitis regressed, and metastatic cancer was detected during subsequent follow-up.

\section{Case report}

A 74-year-old Japanese man visited our ophthalmology clinic in May 2011. He had a history of well controlled type 2 diabetes and colon cancer, which had been treated successfully by surgical removal in 2008. In April, 2011 he was diagnosed as having uveitis in his left eye (Figure 1A) which was unsuccessfully treated with posterior 
sub-Tenon injection of triamcinolone acetonide $20 \mathrm{mg}$. Because of aggravation of the retinal lesion, he was referred to us on May 7, 2011. His best corrected visual acuity was 0.9 OD and 1.2 OS. On slit-lamp examination of the left eye, there were no cells in the anterior chamber, but $1+$ vitreous cells were observed. Funduscopic examination of the left eye revealed arcuate, whitish, necrotizing retinitis with hemorrhage along the temporal arcade of the retina (Figure 1B). On blood investigation, human $\mathrm{T}$ lymphotropic virus-1 antibody and CMV IgG were positive, but human immunodeficiency virus antibody, toxoplasma, herpes simplex virus $\operatorname{IgM} / \mathrm{IgG}$, varicella zoster virus IgM/IgG, and CMV IgM were negative. CD4 was $50.5 \%$ and $\mathrm{CD} 8$ was $21.0 \%$, ie, the $\mathrm{CD} 4 / \mathrm{CD} 8$ ratio was 2.4 (reference range 0.6-2.9). Angiotensin-converting enzyme was $7.2 \mathrm{mU} / \mathrm{mL}$ (reference range 8.3-21.4) and $\mathrm{HbA}_{1 \mathrm{c}}$ was $6.5 \%$ (reference range 4.6-6.2).

On May 11, 2011, $0.1 \mathrm{~mL}$ of aqueous fluid was collected from the left eye by 30 gauge needle under topical anesthesia and submitted for polymerase chain reaction. The result was positive for CMV DNA and negative for herpes simplex and varicella zoster virus DNA. With a diagnosis of CMV retinitis in his left eye, he was referred to an internist before commencement of antiviral treatment to determine if he suffered from systemic CMV infection or any serious disease which could make him immunocompromised, but neither was detected.

Intravitreous injections of ganciclovir $500 \mu \mathrm{g}$ and $1000 \mu \mathrm{g}$ were given on May 25 and June 11, 2011 respectively.
Because of a poor response, oral valganciclovir $1800 \mathrm{mg} /$ day was also initiated on June 28, 2011. This was effective, tapered to $900 \mathrm{mg} /$ day on July 22, 2011, and discontinued on August 20, 2011. A month later the patient's retinitis regressed, and he resumed oral valganciclovir $1800 \mathrm{mg} /$ day on September 22, 2011, which was tapered to $900 \mathrm{mg} /$ day on October 21, 2011. His CMV retinitis regressed again, and he received a third intravitreous ganciclovir injection at a dose of $1000 \mu \mathrm{g}$ on November 17, 2011. Figure 2 shows the course of treatment and Figure 3 shows fundus photographs taken on June 28 and August 20, 2011.

Best corrected visual acuity in his left eye was generally good, (variable between 0.7 and 1.2) except for the last two visits on May 11 and July 4, 2012. By this time he had developed posterior capsular opacification caused by chronic inflammation and senile cataract, and best corrected visual acuity of the left eye was 0.4 on May 11, 2012 and 0.2 on July 4, 2012. He was taking oral valganciclovir $450 \mathrm{mg} /$ day at the last visit, but metastatic liver cancer was found in June 2012, and the patient passed away not long afterwards.

\section{Discussion}

It is now thought that CMV infection in immunocompetent patients is more common than was previously thought. ${ }^{1}$ There have been reports of severe complications of CMV infection, including colitis, meningoencephalitis, pneumonitis, hematological disorders, and venous and arterial thrombosis. ${ }^{1}$

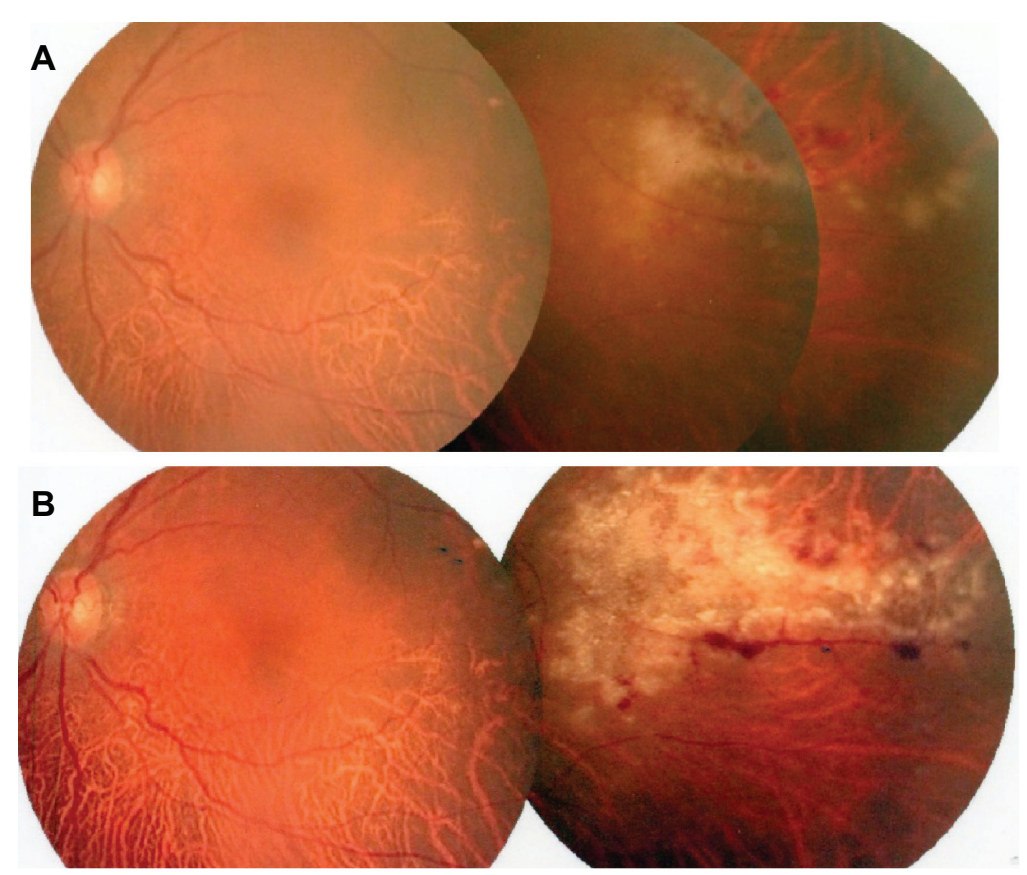

Figure I Fundus photographs of the left eye. (A) Whitish retinitis with slight hemorrhage, observed on April I, 20II. (B) Aggravation of retinitis and hemorrhage on May 6, 201 I (26 days after sub-Tenon injection of triamcinolone acetonide). 


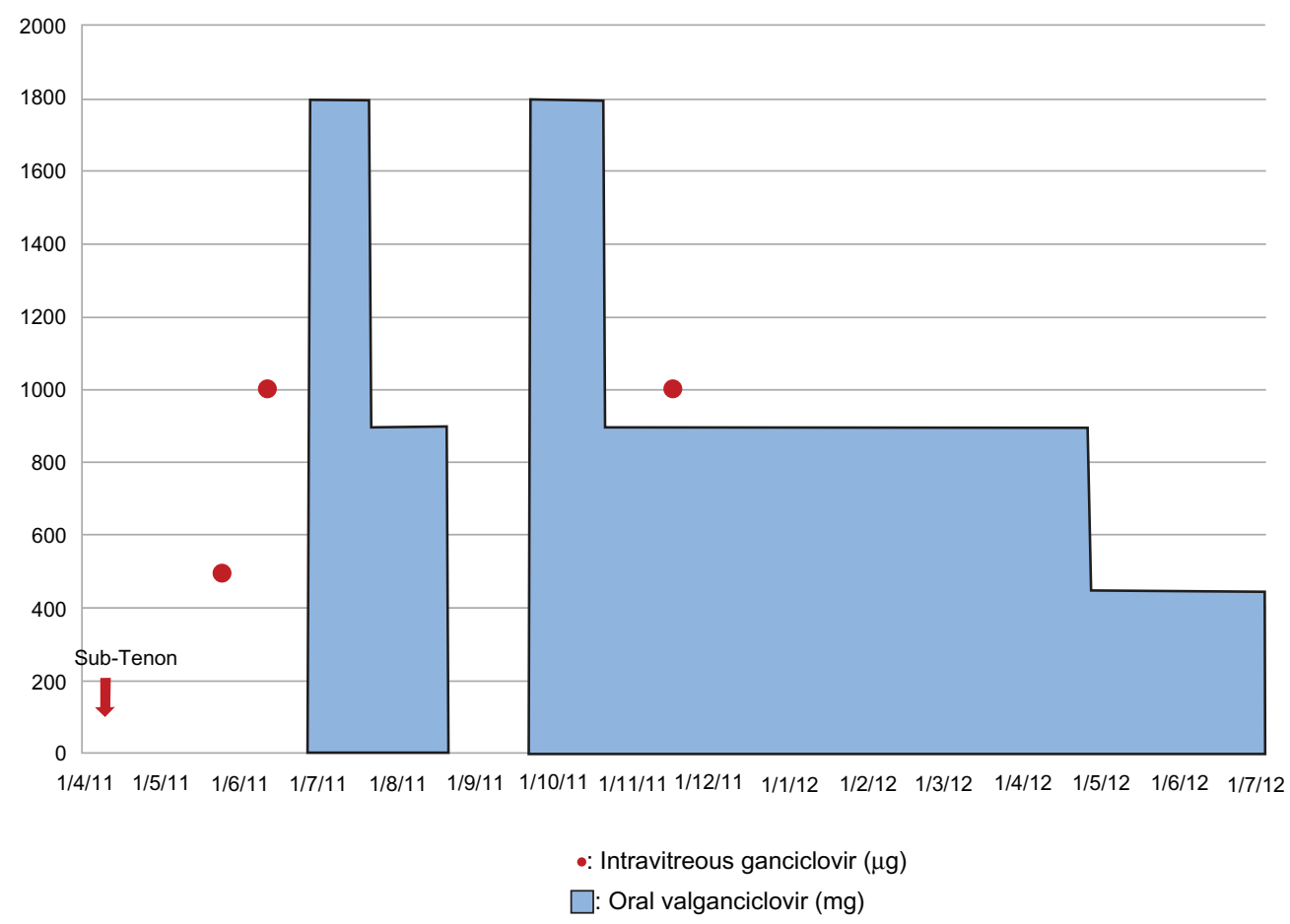

Figure 2 The patient received a course of treatment.

Notes: An arrow shows sub-Tenon injection of triamcinolone acetonide $20 \mathrm{mg}$ on April II, 20I I, and dots show intravitreous ganciclovir injection on May 25, June II and November 17, 201 I. Oral valganciclovir was discontinued on August 20, but resumed at $1800 \mathrm{mg} /$ day on September 22, $201 \mathrm{I}$.

CMV retinitis has been widely believed to affect mainly immunosuppressed patients with acquired immunodeficiency syndrome and a low CD4 cell count, those on long-term treatment with immunosuppressive agents, and neonates. However, there have been several reports of CMV retinitis in immunocompetent patients. ${ }^{1-8}$ These patients had risk factors in common, ie, old age, a history of intraocular surgery, intraocular administration of steroids, and diabetes. ${ }^{1-8}$

It is not clear how CMV becomes reactivated in immunocompetent patients. Sites of chronic infection are known, including monocytes, bone marrow-derived myeloid progenitors, endothelial cells, and the smooth muscle cells of blood vessels. Kercher et al ${ }^{9}$ reported murine CMV persisting in ocular tissue could be reactive, but Vogel et $\mathrm{al}^{10}$ suggested that the human eye (retina) was not a site of persistent CMV infection. Recent studies suggest that CMV retinitis could be caused by infiltration of virus-infected cells circulating in the retina. ${ }^{11}$ It is assumed that reactivated CMV spreads hematologically to infect the retina. In diabetes, it has been reported that leukocytes are less deformable and that circulation of blood in the retina is significantly decreased. ${ }^{12}$ Therefore, leukocytes could be trapped more easily in the capillary circulation of the retina. ${ }^{11}$ Chen et $\mathrm{al}^{13}$ also reported that dyslipidemia
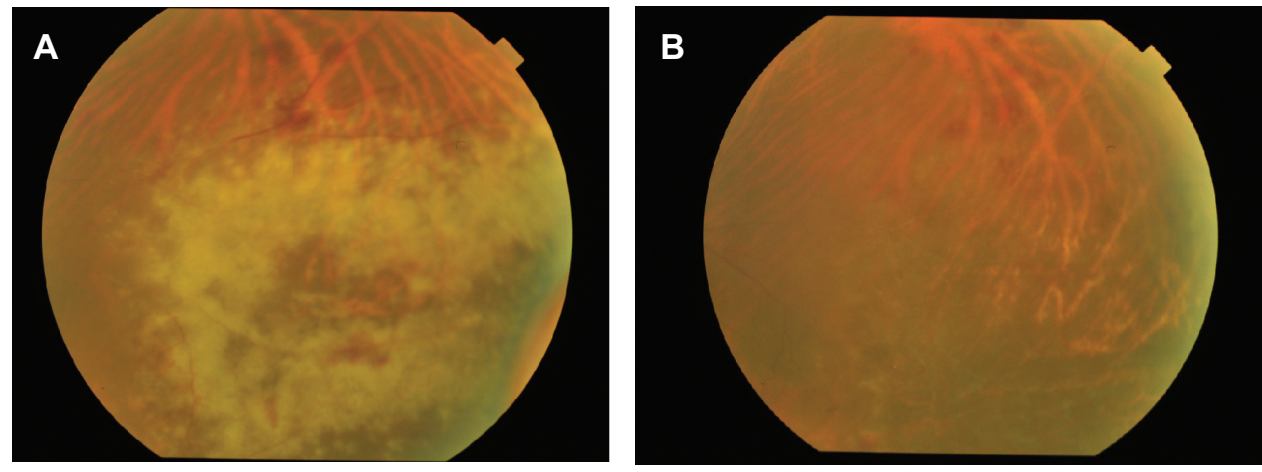

Figure 3 Fundus photographs of the left eye. (A) The retinal lesion did not resolve after intravitreous ganciclovir injection, and oral valganciclovir $1800 \mathrm{mg} /$ day was initiated on June 28, 20II. (B) Resolution of retinitis was observed and valganciclovir was discontinued on August 20, 201 I. 
could induce inflammatory adhesion molecules in human retinal vascular endothelial cells. Dyslipidemia is generally observed in both elderly and diabetic patients, who may be exposed to risk factors for adhesion of activated CMV in the retina.

Immunological status is usually assessed by peripheral blood investigations, which include CD4/CD8 ratio and immunoglobulin levels. In the absence of abnormal findings in these tests or other systemic symptoms, patients are usually deemed to be immunocompetent. Although the present patient had a history of colon cancer, it was treated successfully by surgical removal and he had not taken anticancer medicine for 30 months when he had the initial ocular symptoms. Therefore, he was not considered to be immunosuppressed as a result of colon cancer or its treatment. According to previous reports, the ocular prognosis of CMV retinitis in immunocompetent patients is not serious, and the retinitis can usually be treated successfully by administration of ganciclovir and/or valganciclovir. ${ }^{2-5,7}$ There have also been reports of some cases that did not require antiviral treatment and others in which retinitis has resolved spontaneously with steroid eye drops. ${ }^{6,8}$ Our patient had undergone an intensive course of antiviral treatment with intravitreous ganciclovir and oral valganciclovir, but the retinitis did not resolve, and 14 months after his initial ocular symptoms, colon cancer metastasis to the liver was detected. We suspect that, in spite of the normal CD4/CD8 result, this patient was immunocompromised, at least in the retina, so could not respond adequately to treatment.

According to surveys conducted in Japan and the US, $\mathrm{CMV}$ is a common viral infection. In Japan, Nishimura et $\mathrm{al}^{14}$ reported that the rate of CMV IgG antibody seropositivity was $67.7 \%$ in pregnant women younger than 25 years, and Numazaki et $\mathrm{al}^{15}$ reported that $83.9 \%$ of pregnant women at 10-12 weeks of gestation were seropositive. In the US, Staras et $\mathrm{al}^{16}$ reported that CMV seroprevalence increased gradually with age and was $90.8 \%$ in those older than 80 years. The positive CMV IgG and negative CMV IgM result in our patient indicated that he had been infected by CMV previously. Because he was 74 years of age and diabetic, it is possible that onset of CMV retinitis was associated with his known risk factors of diabetes and old age. Certainly it is important to suspect CMV and obtain aqueous humor for polymerase chain reaction before treatment of retinitis in patients with these risk factors. In addition, it was obvious that this patient's retinitis had been aggravated by sub-Tenon injection of triamcinolone acetonide prior to referral to us. Intraocular steroids have benefits in the treatment of inflammation, although their side effects are also widely recognized. However, because of their simplicity, ophthalmologists are inclined to administer steroids without enough consideration. This could be a trigger for local reactivation of CMV.

According to past reports, the prognosis of CMV retinitis in immunocompetent patients is not critical. In the present case, the patient passed away without complete resolution of his retinitis. It was possible that our early treatment was inadequate, and we could have performed intravitreous ganciclovir injections regularly once a week for induction therapy, as suggested by an earlier study. ${ }^{17}$ However, the patient was diagnosed as immunocompetent at 74 years of age, his visual acuity was good, and he did not want frequent invasive therapy. When CMV retinitis is resistant to antiviral treatment or recurs in an immunocompetent patient, as in this case, it is important for ophthalmologists to order systemic investigations to exclude serious occult disease.

\section{Disclosure}

The authors report no conflicts of interest in this work.

\section{References}

1. Rafailidis PI, Mourtzoukou EG, Varbobitis IC, Falagas ME. Severe cytomegalovirus infection in apparently immunocompetent patients: a systematic review. Virol J. 2008;5:47.

2. Saidel MA, Berreen J, Margolis TP. Cytomegalovirus retinitis after intravitreous triamcinolone in an immunocompetent patient. Am J Ophthalmol. 2005;140(6):1141-1143.

3. Delyfer MN, Rougier MB, Hubschman JP, Aouizérate F, Korobelnik JF. Cytomegalovirus retinitis following intravitreal injection of triamcinolone: report of two cases. Acta Ophthalmol Scand. 2007;85(6): 681-683.

4. Sekiryu T, Iida T, Kaneko H, Saito M. Cytomegalovirus retinitis after intravitreal triamcinolone acetonide in an immunocompetent patient. Jpn J Ophthalmol. 2008;52(5):414-416.

5. Vertes D, Snyers B, De Potter P. Cytomegalovirus retinitis after low-dose intravitreous triamcinolone acetonide in an immunocompetent patient: a warning for the widespread use of intravitreous corticosteroids. Int Ophthalmol. 2010;30(5):595-597.

6. Yoshinaga W, Mizushima Y, Abematsu N, Nakao K, Sakamoto T. Cytomegalovirus retinitis in immunocompetent patients. Nihon Ganka Gakkai Zasshi. 2008;(8):684-687. Japanese.

7. Stewart MW, Bolling JP, Mendez JC. Cytomegalovirus retinitis in an immunocompetent patient. Arch Ophthalmol. 2005;123(4):572-574.

8. Cho WB, Kim HC, Moon JW. Spontaneous resolution of intravitreal steroid-induced bilateral cytomegalovirus retinitis. Korean $J$ Ophthalmol. 2012;26(2):151-155.

9. Kercher L, Mitchell BM. Persisting murine cytomegalovirus can reactivate and has unique transcriptional activity in ocular tissue. J Virol. 2002;76(18):9165-9175.

10. Vogel JU, Fleckenstein C, Wagner M, et al. The human eye (retina): a site of persistent HCMV infection? Graefes Arch Clin Exp Ophthalmol. 2005;243(7):671-676.

11. Miyamoto K, Hiroshiba N, Tsujikawa A, Ogura Y. In vivo demonstration of increased leukocyte entrapment in retinal microcirculation of diabetic rats. Invest Ophthalmol Vis Sci. 1998;39(11):2190-2194. 
12. Schröder S, Palinski W, Schmid-Schönbein GW. Activated monocytes and granulocytes, capillary nonperfusion, and neovascularization in diabetic retinopathy. Am J Pathol. 1991;139(1):81-100.

13. Chen W, Jump DB, Grant MB, Esselman WJ, Busik JV. Dyslipidemia, but not hyperglycemia, induces inflammatory adhesion molecules in human retinal vascular endothelial cells. Invest Ophthalmol Vis Sci. 2003;44(11):5016-5050.

14. Nishimura N, Kimura H, Yabuta Y, et al. Prevalence of maternal cytomegalovirus (CMV) antibody and detection of CMV DNA in amniotic fluid. Microbiol Immunol. 1999;43(8):781-784.
15. Numazaki K, Fujikawa T, Chiba S. Relationship between seropositivity of husbands and primary cytomegalovirus infection during pregnancy. $J$ Infect Chemother. 2000;6(2):104-106.

16. Staras SA, Dollard SC, Radford KW, Flanders WD, Pass RF, Cannon MJ. Seroprevalence of cytomegalovirus infection in the United States, 1988-1994. Clin Infect Dis. 2006;43(9):1143-1151.

17. Cochereau-Massin I, Lehoang P, Lautier-Frau M, et al. Efficacy and tolerance of intravitreal ganciclovir in cytomegalovirus retinitis in acquired immune deficiency syndrome. Ophthalmology. 1991; 98(9):1348-1353.
Clinical Ophthalmology

\section{Publish your work in this journal}

Clinical Ophthalmology is an international, peer-reviewed journal covering all subspecialties within ophthalmology. Key topics include: Optometry; Visual science; Pharmacology and drug therapy in eye diseases; Basic Sciences; Primary and Secondary eye care; Patien Safety and Quality of Care Improvements. This journal is indexed on

Submit your manuscript here: http://www.dovepress.com/clinical-ophthalmology-journal

\section{Dovepress}

PubMed Central and CAS, and is the official journal of The Society of Clinical Ophthalmology (SCO). The manuscript management system is completely online and includes a very quick and fair peer-review system, which is all easy to use. Visit http://www.dovepress.com/ testimonials.php to read real quotes from published authors. 